Supplement of Hydrol. Earth Syst. Sci., 23, 2129-2146, 2019

https://doi.org/10.5194/hess-23-2129-2019-supplement

(c) Author(s) 2019. This work is distributed under

the Creative Commons Attribution 4.0 License.

(c) (1)

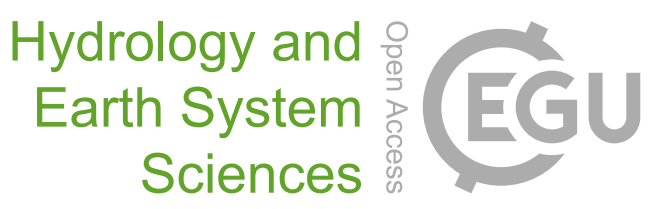

Supplement of

\title{
Unexplained hydrogen isotope offsets complicate the identification and quantification of tree water sources in a riparian forest
}

Adrià Barbeta et al.

Correspondence to: Adrià Barbeta (adria.barbeta-margarit@inra.fr) and Jérôme Ogée (jerome.ogee@inra.fr)

The copyright of individual parts of the supplement might differ from the CC BY 4.0 License. 
Table S1: Soil properties of the three differentiated horizons in the studied plots. Values are obtained from pooled samples from all the sites where soil was sampled for stable isotopes.

\begin{tabular}{|c|c|c|c|c|c|c|c|c|c|c|}
\hline Horizon & $\begin{array}{l}\text { Depth } \\
(\mathrm{cm})\end{array}$ & $\begin{array}{l}\text { Clay } \\
(\text { g.kg-1) }\end{array}$ & $\begin{array}{l}\text { Fine silt } \\
\text { (g.kg-1) }\end{array}$ & $\begin{array}{l}\text { Coarse silt } \\
\text { (g.kg-1) }\end{array}$ & $\begin{array}{l}\text { Fine sand } \\
\text { (g.kg-1) }\end{array}$ & $\begin{array}{l}\text { Coarse sand } \\
\text { (g.kg-1) }\end{array}$ & $\begin{array}{l}\text { Carbon } \\
\text { (g.kg-1) }\end{array}$ & $\begin{array}{l}\text { Nitrogen } \\
\text { (g.kg-1) }\end{array}$ & $\begin{array}{l}\mathrm{CaCO} 3 \\
\text { (g.kg-1) } \\
\end{array}$ & $\mathrm{pH}$ \\
\hline A & $0-10$ & 44 & 16 & 9 & 106 & 825 & 17.3 & 0.52 & 75 & 8.05 \\
\hline B & $10-50$ & 37 & 24 & 6 & 115 & 818 & 19.4 & 0.792 & 37 & 7.93 \\
\hline $\mathrm{C}$ & $50-120$ & 81 & 93 & 39 & 455 & 332 & 52.2 & 0.467 & 388 & 8.24 \\
\hline
\end{tabular}

Table S2: Output of the general linear model for the SW-excess and its explanatory variables. The $\beta$ coefficient is the standardized correlation coefficient for each of the independent variables. The estimate of 'Sampled xylem' is the difference in SW-excess of coarse roots respect to twigs, and that of 'Species' is the difference in $\mathrm{SW}$-excess between $Q$. robur respect to $F$. sylvatica.). The $R^{2}$ of the model was $33.3 \%$.

\begin{tabular}{|c|r|r|r|r|r|}
\hline Variable & Estimate & $\beta$ coefficient & \multicolumn{1}{|c|}{ Std. Error } & \multicolumn{1}{c|}{$t$-value } & $P$-value \\
\hline (Intercept) & -5.753 & - & 1.601 & -3.593 & $<0.0001$ \\
\hline Top soil water content (log) & 2.024 & 0.180 & 0.612 & 3.305 & 0.001 \\
\hline Sampled xylem (coarse roots) & -6.720 & -0.451 & 0.730 & -9.210 & $<0.0001$ \\
\hline Species (Q. robur) & 1.069 & 0.092 & 0.562 & 1.901 & 0.058 \\
\hline Rainfall & -0.137 & -0.407 & 0.019 & -7.146 & $<0.0001$ \\
\hline Top soil water $\delta^{2} \mathrm{H}$ & -0.141 & -0.244 & 0.030 & -4.698 & $<0.0001$ \\
\hline VPD & -2.184 & -0.123 & 0.896 & -2.437 & 0.015 \\
\hline
\end{tabular}


Table S3. Intercepts, estimates (slopes), $\boldsymbol{R}^{2}$ and $\boldsymbol{P}$-values of the linear regression of soil water lines built with top and deep soil isotopic data, for each sampling date and plot separately.

\begin{tabular}{|c|c|c|c|c|c|c|c|c|c|c|c|c|}
\hline \multirow[b]{2}{*}{ Date } & \multicolumn{4}{|c|}{ Plot 1} & \multicolumn{4}{|c|}{ Plot 2} & \multicolumn{4}{|c|}{ Plot 3} \\
\hline & Intercept & Estimate & $R^{2}$ & $P$-value & Intercept & Estimate & $R^{2}$ & $P$-value & Intercept & Estimate & $R^{2}$ & $P$-value \\
\hline $4 / 19 / 2017$ & -26.612 & 2.971 & 0.544 & 0.263 & -22.778 & 3.333 & 0.798 & 0.017 & -28.795 & 2.367 & 0.945 & 0.001 \\
\hline $5 / 5 / 2017$ & -3.840 & 5.998 & 0.997 & $<0.00001$ & -13.286 & 5.000 & 0.897 & 0.004 & -10.519 & 4.689 & 0.952 & 0.001 \\
\hline $5 / 23 / 2017$ & 3.465 & 7.764 & 0.692 & 0.040 & -20.144 & 4.259 & 0.741 & 0.061 & -3.407 & 6.419 & 0.421 & 0.163 \\
\hline $6 / 7 / 2017$ & -23.919 & 2.927 & 0.781 & 0.019 & -33.387 & 0.248 & 0.005 & 0.891 & -11.947 & 4.588 & 0.878 & 0.002 \\
\hline $6 / 21 / 2017$ & -28.839 & 1.984 & 0.897 & 0.004 & -23.417 & 2.533 & 0.679 & 0.044 & -18.977 & 3.325 & 0.954 & 0.001 \\
\hline $7 / 4 / 2017$ & 13.527 & 9.097 & 0.741 & 0.028 & -18.036 & 4.147 & 0.707 & 0.036 & 2.349 & 7.626 & 0.835 & $\mathbf{0 . 0 0 4}$ \\
\hline $7 / 26 / 2017$ & -17.417 & 4.604 & 0.836 & 0.004 & -26.810 & 2.456 & 0.603 & 0.069 & -25.229 & 3.155 & 0.769 & 0.010 \\
\hline $8 / 9 / 2017$ & -0.668 & 7.616 & 0.772 & 0.050 & -29.539 & 2.333 & 0.931 & 0.002 & -18.890 & 3.973 & 0.823 & 0.013 \\
\hline $8 / 22 / 2017$ & -28.511 & 2.768 & 0.685 & 0.042 & -31.312 & 1.931 & 0.763 & 0.023 & -17.955 & 4.277 & 0.959 & $\mathbf{0 . 0 0 4}$ \\
\hline $9 / 12 / 2017$ & -13.187 & 5.110 & 0.822 & 0.013 & -28.886 & 2.680 & 0.579 & 0.239 & -11.174 & 4.987 & 0.891 & 0.001 \\
\hline $9 / 26 / 2017$ & -15.638 & 3.795 & 0.544 & 0.094 & -22.838 & 2.262 & 0.291 & 0.211 & -4.122 & 6.210 & 0.996 & $<0.00001$ \\
\hline $10 / 12 / 2017$ & -10.401 & 4.755 & 0.954 & 0.001 & -14.206 & 4.071 & 0.853 & 0.003 & -2.587 & 6.336 & 0.950 & 0.001 \\
\hline $10 / 25 / 2017$ & -11.937 & 4.891 & 0.923 & 0.002 & -14.937 & 4.381 & 0.837 & 0.011 & -9.319 & 5.278 & 0.847 & $\mathbf{0 . 0 0 9}$ \\
\hline $11 / 9 / 2017$ & -4.423 & 5.637 & 0.651 & 0.052 & -1.214 & 6.529 & 0.879 & 0.062 & -8.947 & 4.889 & 0.805 & $\mathbf{0 . 0 3 9}$ \\
\hline
\end{tabular}



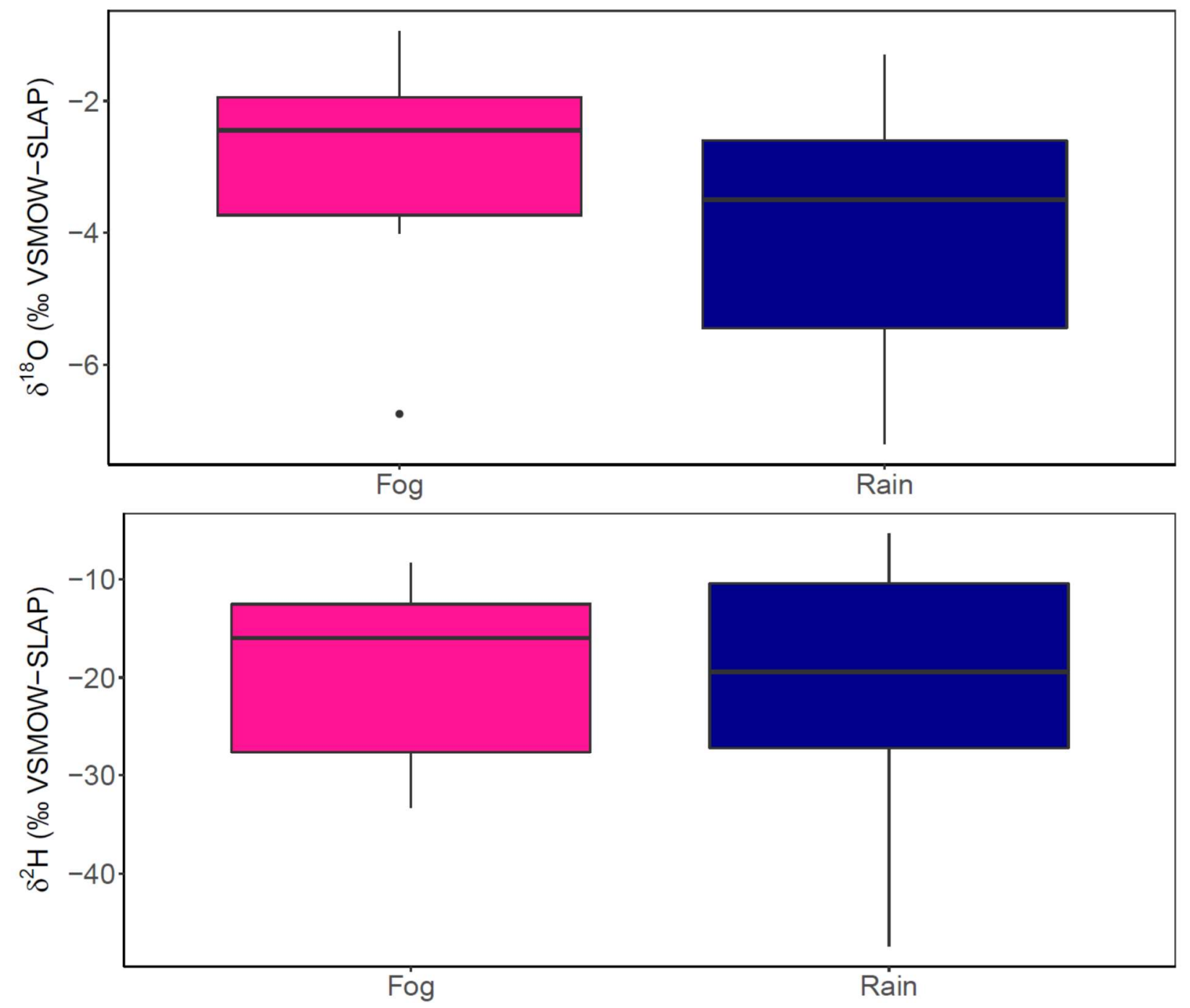

Figure S1: Comparison of water stable isotopes of fog and rain for the samples collected in 2017 in the Ciron. Box size represents the interquartile range, the black line is the median, the whiskers indicate variability outside the upper and lower quartiles, and individual points are outliers. 


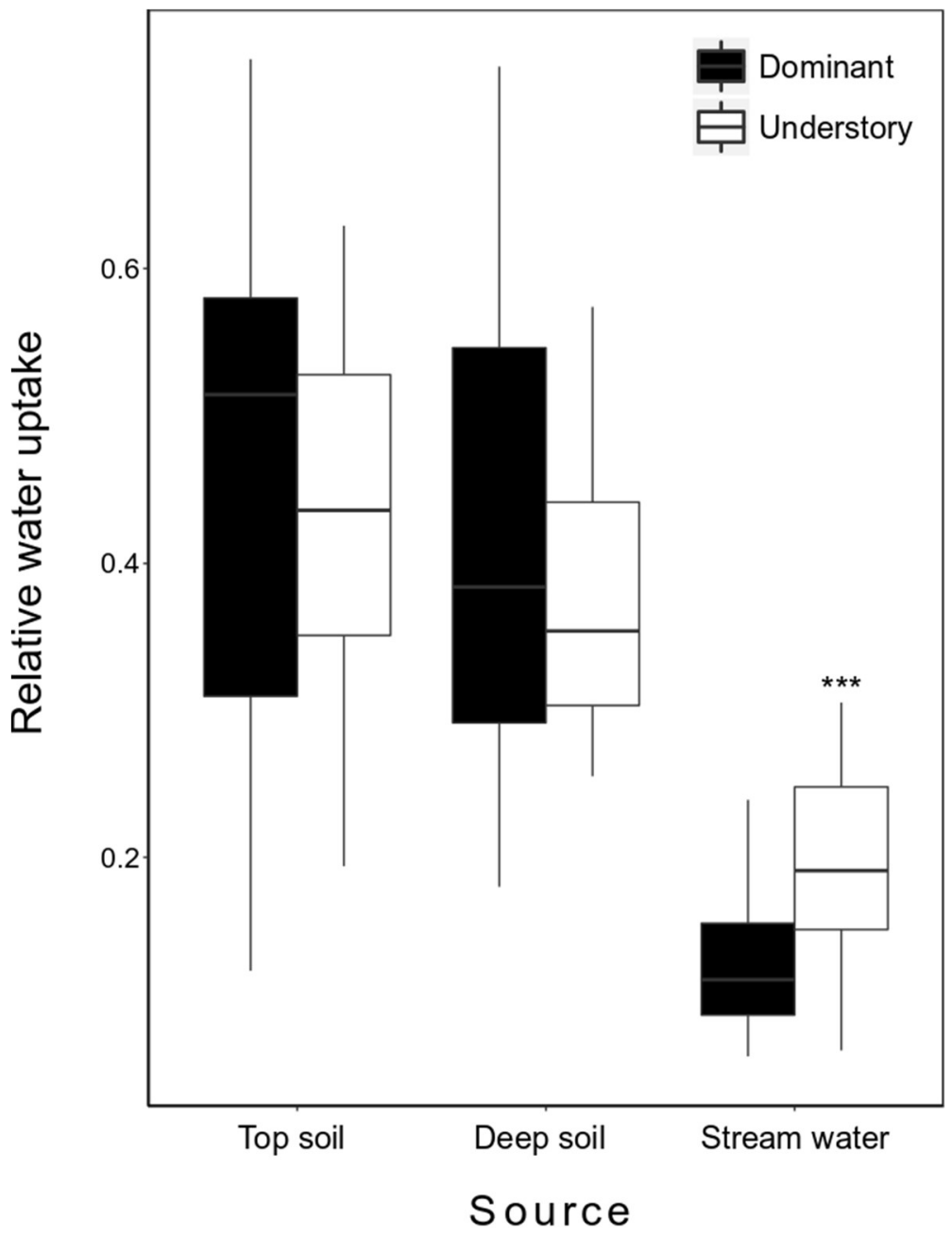

Figure S2: Comparison between the proportion of each plant-water source of dominant and understory. Box size represents the interquartile range, the black line is the median, the whiskers indicate variability outside the upper and lower quartiles, and individual points are outliers. Significant differences between canopy positions are highlighted with $* * *(P<0.001)$. 